\title{
TEMÁTICA INDÍGENA E EXTENSÃO UNIVERSITÁRIA: um olhar para os editais da Pró-Reitoria de Extensão e Cultura do IFPB
}

\author{
THE INDIGENOUS THEME AND UNIVERSITY EXTENSION: a look at the \\ public notifications of the Sub Rectory of Extension and Culture, IFPB
}

Humberto Bismark Silva Dantas*

\section{Resumo}

Este trabalho emerge a partir da lei 11.645/2008, pautando a interface da extensão no IFPB como espaço propício ao desenvolvimento de atividades vinculadas ao ensino de temática indígena. É resultado das experiências vividas no projeto "Por dentro do IFPB Conhecer e expressar", realizadas no âmbito do Programa de Bolsas de Iniciação à Docência PIBID/Sociologia - UFPB, sob coordenação dos professores Rita de Cássia Melo Santos (DCS/UFPB) e Adolfo Wagner (IFPB). Metodologicamente, realizo um mapeamento das iniciativas da Pró-reitoria de Extensão e Cultura (PROEX) de toda a rede do IFPB, especialmente no que se refere aos editais de Projetos, Programas, Eventos e Prestação de Serviços, entre os anos de 2016 a 2019. Das 855 ações financiadas nesses editais, apenas 19 (2,22\% do total) se vinculam aos povos indígenas, das quais 13 possuem propostas de colaboração direta junto aos Potiguara e/ou Tabajara da Paraíba. Entre essas 13 ações encontramos movimentos de auxílio técnico especializado por meio dos cursos dentro do IFPB, bem como ações de promoção à mobilização cultural e cidadã dentro e fora das aldeias. Os 6 projetos restantes se vinculam a ações de ensino de cultura e história indígena, seja no próprio IFPB, em escolas da região ou em ações de etnoturismo em sítios arqueológicos do estado. Por fim, constatamos a urgência de ampliação de fomento institucional ao lidar com a temática indígena de forma multilateral, em ações de Ensino, Pesquisa e Extensão. Paralelamente, ganham luz os desafios enfrentados pelas universidades e institutos federais frente ao desmonte da educação pública após o golpe de 2016, intensificando, por exemplo, a redução das já incipientes iniciativas de extensão voltadas à temática indígena.

Palavras-chave: Povos Indígenas; Lei 11.645; Extensão e Cultura; Ensino de Sociologia.

\begin{abstract}
This work emerges from government decree 11.645 / 2008, guiding the extension project at IFPB as a conducive space for the development of activities related to the teaching of indigenous themes. It is the result of experiences lived on the project: Inside IFPB - know and express, carried out under the Teaching Initiation Scholarship Program (PIBIDSociology - UFPB), under the coordination of professors Rita de Cássia Melo Santos (DCS/UFPB) and Adolfo Wagner (IFPB). Methodologically, we carried out a mapping

\footnotetext{
* Aluno do Curso de Licenciatura em Ciências Sociais da UFPB e pesquisador vinculado ao Grupo Interdisciplinar de Pesquisa em Cultura, Sociedade e Ambiente (GIPCSA). E-mail: humbertobsdantas@gmail.com
} 
of the initiatives of the Sub-Rectory of Extension and Culture (PROEX) of the entire IFPB network, especially with regard to the public notifications of Projects, Programs, Events and Provision of Services, between the years 2016 to 2019. Of the 855 actions financed in these public notifications, only 19 (2.22\% of the total) are linked to indigenous peoples, of which 13 have proposals for direct collaboration with the Potiguara and/or Tabajara of Paraíba. Among these 13 actions, we find specialized technical assistance initiatives through courses within the IFPB, as well as actions to promote cultural and citizen mobilization inside and out of the indigenous villages. The remaining 6 projects are linked to initiatives to teach indigenous culture and history, whether at the IFPB itself, at nearby schools or in ethno tourism actions at archaeological sites in the state. Finally, we note the urgency of expanding institutional promotion when dealing with the indigenous theme in a multilateral way, in initiatives of Teaching, Research and Extension. At the same time, the challenges faced by Federal Universities and institutes in the face of the dismantling of public education after the 2016 coup are highlighted; measures which aggravate the reduction of the already incipient extension initiatives aimed at indigenous themes.

Keywords: Indigenous Peoples; Government Decree 11,645; Extension and Culture; Sociology Teaching.

\section{0 ensino da temática indígena e o atualizar de velhos preconceitos}

Assim como acontece de uma forma geral com as populações não-brancas no Brasil, os povos indígenas são postulados por intermédio de uma série de estigmas e generalizações que não se aplicam à diversidade de suas realidades. João Pacheco de Oliveira (2016), no livro 'O nascimento do Brasil', se debruça sobre essa inserção de indígenas no imaginário nacional brasileiro construído desde o início da invasão colonizadora. Uma de suas principais teses é a de que a participação desses povos tem se colocado enquanto "um ponto cego constantemente repetido e naturalizado nas grandes interpretações sobre o Brasil” (OLIVEIRA, 2016, p. 12). A pluralidade étnico-racial originária no território brasileiro foi violentamente invisibilizada, sendo posta num plano secundário na hegemônica narrativa de construção do Brasil-Nação. Dessa forma, ainda na contemporaneidade, ocorre a manutenção da imagem dos indígenas estagnada num passado romântico, confluindo na manutenção preconceituosa do estigma do 'índio genérico’ no sentido defendido pelo antropólogo Gersem Luciano Baniwa (BANIWA, 2006).

Enquanto docentes e produtores de conhecimento entrelaçados junto aos povos originários de Abya Yala, faz-se importante a construção de um posicionamento banhado no compromisso epistemológico junto a essas populações. Percebemos uma série de 
esforços sendo movidos por parte dos movimentos indígenas e de seus apoiadores, numa busca pela quebra desses paradigmas preconceituosos, pautando enfaticamente a visibilização da real diversidade sociocultural contemporânea. Percebemos que

não há uma só história indígena no Brasil, mas uma multiplicidade de histórias,
tecidas com experiências desenvolvidas em temporalidades diversas, em
ecossistemas e modos de colonização diferentes, resultando em formas
organizativas, tradições culturais e horizontes políticos também muito distintos
(OLIVEIRA, 2016, p. 39).

Em consonância, Grupioni (1995) destaca a existência de alguns dessas tentativas contra hegemônicas em 1990, momento crescente das discussões em fóruns e eventos voltados à causa indígena, incluindo maneiras de estruturação de uma educação escolar não-indígena que englobasse o respeito à diversidade étnica brasileira. $\mathrm{O}$ pesquisador traz à tona a reverberação do/as indígenas uniformizados/as em uma imagem exótica tanto nas escolas básicas quanto nos meios de comunicação cotidianos. Sendo assim, notamos a manutenção deficitária no sistema educacional básico, visto que o debate crítico é frequentemente contornado nas escolas, perdendo espaço para a concepção limitante atrelada à imagem do indígena estigmatizado.

No livro "O índio brasileiro: o que você precisa saber sobre os povos indígenas no Brasil de hoje", Gersem Luciano Baniwa (2006) alerta sobre a necessidade de percebermos a inexistência desse "índio genérico", posicionando-o como mais uma das formas de violência vivenciadas a partir do apagamento histórico das existências indígenas. Para o pesquisador, as reverberações, no que tange a esse estigma, são "fruto do preconceito de que índio é tudo igual, servindo para diminuir o valor e a riqueza da diversidade cultural dos povos nativos e originários da América continental" (BANIWA, 2006, p. 40).

Essa concepção alinha-se ao que afirma Silva, ao destacar que a negação das “identidades dos povos indígenas é a condição para omitir seus direitos" (SILVA, E., 2017, p. 99), sendo utilizada constantemente para deslegitimar suas existências. De acordo com esses dois pesquisadores, esse processo se intensifica ainda mais ao pensarmos o Nordeste, onde temos um violento processo posto pelo longo período de invasão colonial do território originário de vários povos, tendo como resultado o etnocídio de diversas etnias, mesmo diante da resistência de outras tantas. O estado da Paraíba não foge dessa afirmativa. Oficialmente, encontramos apenas duas populações indígenas no 
território paraibano - os Potiguara do litoral Norte, nas cidades de Rio Tinto, Marcação e Baía da Traição, e os Tabajara do litoral Sul, no Conde, tendo apenas os Potiguara suas terras oficialmente demarcadas ou em processo de homologação.

O trabalho que ora apresento emerge na busca de uma compreensão crítica acerca da inserção do Instituto Federal da Paraíba (IFPB) no contexto aqui abordado, percebendo as possibilidades de diálogo com as populações indígenas presentes no território paraibano. Partimos das experiências realizadas no IFPB/Campus João Pessoa, no âmbito do projeto "Por dentro do IFPB - Conhecer e expressar", seção do Programa Institucional de Bolsas de Iniciação à Docência (PIBID), sob orientação dos professores Rita de Cássia Melo Santos (DCS/UFPB) e Adolfo Wagner (IFPB). As atividades do PIBID/Sociologia foram construídas sob a ótica da pesquisa alinhada à formação em licenciatura, alçando sobre a necessidade de capacitação de professores/as-pesquisadores/as no âmbito das ciências sociais. Os esforços desse trabalho inserem-se no projeto no intuito de conhecer o IFPB, evidenciando a importância da pesquisa nos contextos escolares como recurso potencializador da ação efetiva de discentes nas escolas, principalmente no que tange ao ensino de sociologia. Esse trabalho traça caminhos entre as ações de extensão dos campus do IFPB e suas relações com indígenas Potiguara e Tabajara do estado da Paraíba. Evidencio a importância de pautar o ensino de relações étnico-raciais para além da sala de aula, abrangendo de forma transversal as plataformas da educação escolar nãoindígena, em consonância com a Lei 11.645/2008 (BRASIL, 2008) e com os pressupostos de uma escola comprometida com a construção do conhecimento crítico, nesse caso direcionado especificamente às ações alinhadas ao ensino de história e cultura indígena no contexto dos Institutos Federais da Paraíba.

As minhas atividades do PIBIB/Sociologia no IFPB foram iniciadas em uma investigação sobre as formas de ensino de sociologia frente à temática indígena no campus João Pessoa. Em meio a revisões bibliográficas e diálogos com alguns/mas professores/as de sociologia, percebi a existência de pesquisas voltadas ao ensino de temática indígena em disciplinas como história, artes, português e na própria sociologia. Alinhado a isso, na primeira parte desse trabalho exploro como essas pesquisas apontam que, mesmo em meio a alguns avanços, prevalece um descompasso em relação ao proposto pela Lei 11.645/2008 e a construção de um conhecimento crítico e antirracista 
nas escolas. Tendo isso como pressuposto, em reuniões de orientação e discussão em grupo com participantes do PIBID/Sociologia, optei por redirecionar a pesquisa no sentido de investigar especificamente as ações de extensão, por meio da análise dos resumos dos projetos, programas, eventos e prestações de serviços financiados no período 2016-2019. Essa análise conflui na segunda parte deste trabalho. Por último, trago os apontamentos finais relativos a esta pesquisa, alinhando o que foi discutido à entrevista realizada junto a Roberta Paiva Cavalcante, responsável pela Coordenação de Extensão, Cultura e Desafios Acadêmicos do IFPB/João Pessoa.

\subsection{Povos indígenas e interfaces do ensino: caminhos guiados pela Lei $11.645 / 2008$}

Dentre os esforços mobilizados pelos movimentos indígenas instauram-se algumas políticas voltadas à garantia de direitos, nessa direção encontramos um ponto de ruptura em relação ao ensino da questão indígena nas escolas com a promulgação da Lei 11.645/2008. Além de levar em consideração os aspectos referentes à importância dos povos afro-brasileiros, a lei citada altera a 10.639/2003, de modo a consolidar a necessidade de enfatizar também a importância dos povos indígenas na formação da sociedade brasileira e suas movimentações políticas na atualidade, assim estabelece nova redação para o Art. 26-A da Lei 9.394/96 (Lei de Diretrizes e Bases da Educação Nacional):

o conteúdo programático a que se refere este artigo incluirá diversos aspectos da história e da cultura que caracterizam a formação da população brasileira, a partir desses dois grupos étnicos, tais como o estudo da história da África e dos africanos, a luta dos negros e dos povos indígenas no Brasil, a cultura negra e indígena brasileira e o negro e o índio na formação da sociedade nacional, resgatando as suas contribuições nas áreas social, econômica e política, pertinentes à história do Brasil (BRASIL, 2008).

Com a sua promulgação, pauta-se veementemente a construção de alternativas voltadas ao ensino crítico de questões indígenas nas escolas indígenas e não-indígenas. De acordo com Edson Silva (SILVA, 2017), a lei fomenta a construção de conhecimento em sala a partir das realidades plurais vivenciadas pelos povos indígenas no Brasil. Destaca-se a importância de abordar a pluralidade de formas de existência dos povos originários, não somente em relação a não-indígenas, mas também de acordo com as diversidades étnicas existente entre esses diversos povos. 
No debate acerca do ensino específico de sociologia, cabe enfatizar que a lei torna obrigatório o ensino de história indígena nas disciplinas Educação Artística, Linguagens e História Brasileira, mas deixa abertura para o ensino transversal, englobando todas as disciplinas do ensino básico. Apesar disso, deve-se ter em mente que o ensino de sociologia veio se tornar obrigatório num momento posterior aos tramites referentes à lei que engloba o ensino da questão indígena nas escolas, entendemos que não havia possibilidade da lei prever reflexos diretos no ensino de sociologia sem sua efetiva obrigatoriedade, instaurada apenas com a promulgação da lei 11.684/08 (ocorrida em junho de 2008, 3 meses após a aprovação da Lei 11.645/08). De todo modo, evidenciamos a importância da disciplina sociologia e seu esforço em quebrar os paradigmas hegemônicos ao lidarmos com as temáticas indígenas, haja vista sua longa relação de colaboração e elaboração de pesquisas junto a essas populações, especialmente em perspectiva antropológica, culminando diretamente na disciplina de sociologia no ensino médio.

Podemos afirmar a existência de um paralelo na relação entre a efetivação lenta da lei de obrigatoriedade do ensino de sociologia e a lei de ensino da temática indígena, ambas promulgadas no ano de 2008. Taise Chates evidencia que mesmo com a análise relativamente recente, já se faz urgente a necessidade de investigarmos as propostas efetivas, percebendo o traçar de novos caminhos do ensino da questão indígena a partir da sociologia. Para a pesquisadora, não precisamos de muitos esforços para perceber que "ainda há muito por caminhar para consolidar novamente as ciências sociais como disciplina no ensino médio" e que, junto a isso o ensino de temática indígena tem se movimentado lentamente de modo que "se avançou muito pouco em direção à implementação da Lei 11.645/08" (CHATES, 2015, p. 137). Defendendo o vínculo direto entre uma concretização efetiva dessas duas leis, Chates traz à tona

\footnotetext{
a importância de abordar a sociologia de maneira conectada ao cotidiano e às questões mais amplas que interferem diretamente nas transformações sociais [...] para tanto, é imprescindível encampar a luta por escolas transformadoras e não conservadoras, que desnaturalizem as relações sociais de exploração e opressão, bem como os estigmas e as violências que vêm atingindo os povos indígenas (CHATES, 2015, p. 137).
}

Em meio a evidenciação dos/as indígenas em seus contextos reais, devemos perceber também a necessidade de pautar esse ensino de forma crítica. Nessa direção, 
Faisting e Aguiar (2018) trazem à tona o teor "eurocêntrico e colonial" dos conteúdos didáticos para ensino de temática indígena e afro-brasileira. A partir da experiência do PIBID de Sociologia da UFGD, o autor e a autora evidenciam a importância da inserção da temática indígena no âmbito da sociologia, especialmente visando à desconstrução dos estigmas, e pautados pela efetivação de uma sociologia crítica. Devemos ir além da mera abordagem da temática étnico-racial, "torna-se indispensável considerar a importância desses instrumentos para ampliação do conhecimento sociológico sobre a existência e o combate ao racismo" (FAISTING; AGUIAR, 2018, p. 8).

Apesar dos avanços contínuos oriundos dos estudos realizados em conjunto entre universidade e povos indígenas, ao investigamos sobre o ensino dessa temática em sala de aula na educação básica, acabamos encontrando a manutenção de preconceitos que já foram superados amplamente em espaços de diálogos construídos em colaboração com o movimento indígena nas ciências humanas. Grupioni (1995) afirma que o conhecimento produzido pelos espaços acadêmicos ainda estava distante de saltar os muros da academia, mesmo que naquele momento houvesse uma iniciativa mínima para que esse conhecimento chegasse às mãos de professores/as e causasse impactos positivos. No ano de 1995, o pesquisador já enfatizava a necessidade de investir esforços na publicização dos conhecimentos produzidos no âmbito acadêmico, deixando claro que cabe a pesquisadores envolvidos com esses povos se comprometerem e se mobilizarem para produzir materiais que venham a servir de subsídios para o ensino escolar, rompendo as fronteiras tradicionais do conhecimento circular produzido e consumido apenas por especialistas.

Maria da Penha da Silva (SILVA, M., 2010), quinze anos após a afirmação de Grupioni (1995), reforça a existência desse descompasso. A pesquisadora enfatiza a falta de investimento em materiais didáticos úteis para a inserção da temática indígena nas escolas de modo realmente efetivo. Com a promulgação da lei, aumentou-se a presença de informações sobre os povos originários nos livros didáticos, no entanto, "são conteúdo que relatam situações do passado, trazem informações comuns aos primeiros manuais didáticos" (SILVA, M., 2010, p. 223). Apesar disso, a pesquisadora deixa claro que ocorreram mudanças nos dois primeiros anos posteriores à instauração da lei 11.645/08 
referentes ao aumento quantitativo do número de menções aos povos indígenas nos livros didáticos.

Já em pesquisa mais recente, Soares (SOARES, V., 2020) nos mostra que ainda prevalece a manutenção dos conteúdos voltados à reprodução de estereótipos que negam a diversidade indígena nos livros didáticos, mesmo frente a algumas iniciativas efetivas. Ao analisar os livros de sociologia aprovados no Plano Nacional do Livro Didático (PNLD) de 2012, 2015 e 2018, com livros publicados antes e depois da promulgação da Lei 11.645/2008, a pesquisadora aponta que:

\begin{abstract}
A forma como os indígenas são colocados, mesmo quando aparecem no tempo presente, é como se estivessem muito distantes da sociedade. O que concluímos dos três livros analisados é a permanência de uma perspectiva homogeneizadora e genérica que ainda recorre a estereótipos, embora haja um esforço para trabalhar de forma positiva os povos indígenas. Os livros também são deficientes no que diz respeito à diversidade e quantidade de povos indígenas. As imagens que aparecem são de indígenas do Centro-Oeste e Norte, e nem ao menos mencionam os indígenas do Nordeste, apesar de serem o segundo maior contingente populacional indígena do Brasil (SOARES, V., 2020. p. 88).
\end{abstract}

Acerca das reflexões sobre o ensino, Kelly Russo e Mariana Paladino (RUSSO; PALDINO,2016) trazem uma abrangente pesquisa a partir de entrevistas com 100 professores/as do ensino fundamental público do estado do Rio de Janeiro. As pesquisadoras constataram que os livros didáticos acabam sendo bastante utilizados em sala, mesmo não estando atualizados, e trazendo a manutenção do olhar do estigma junto aos povos indígenas. Paralelamente os/as professores/as enfatizam críticas em relação ao material disponibilizado nos livros. Destaca-se a disposição dos/as professores/as em abordar temática indígena em suas escolas mesmo diante da falta de apoio institucional para isso, as ações acabam se resumindo a eventos pontuais desenvolvidos sem fortalecimento em rede ou continuidade do apoio institucional. As pesquisadoras atentam para a necessidade de não colocarmos esse desfalque apenas na conta do corpo docente, também devemos pensar na importância das questões institucionais sob responsabilidade da administração das escolas e do poder público, a exemplo da indisponibilidade de materiais de qualidade, ou mesmo a deficiência de formação docente contínua referente à temática aqui abordada.

Diante dessas nuances não podemos cair no ideal simplista de que a promulgação da lei acabou se moldando em uma simples "lei morta", na qual não se percebem 
mudanças positivas. A problemática ampliação da presença dos povos indígenas nos livros didáticos explicitada por Luís Grupioni (1995), Maria da Penha da Silva (2010) e por Valclecia Soares (2020), assim como a disposição por realizar atividades individualmente por parte dos/as professores/as entrevistados/as por Kelly Russo e Mariana Paladino (2016) e diversos outros trabalhos voltados a pensar a efetivação da lei 11.645/2008, são iniciativas palpáveis que demonstram o lento avanço em direção à concretização do que está proposto.

Assim como as ações construídas por Faisting e Aguiar (2018), a seguir abordo duas inciativas significativas que se aplicam à interface da tríade de Ensino, Pesquisa e Extensão em Instituições Federais. A mais recente é a disciplina "Educação para as Relações Étnico-raciais", ministrada pela pesquisadora Paula Santana (SANTANA, 2017) para discentes da licenciatura na Universidade Federal Rural de Pernambuco. Santana traz depoimentos de alunos/as mostrando como uma disciplina específica voltada às relações étnico-raciais vem a pesar positivamente na formação docente. Molda-se um esforço que capacita futuros licenciados para lidar com a temática indígena de forma efetiva em sala, além de contextualizar a questão indígena no território onde a UFRPE está inserida, percebendo a relevância de suas lutas contemporâneas por território e por reconhecimento étnico.

Na mesma direção, utilizando da interface de pesquisa e extensão no Instituto Federal da Bahia (IFBA), Taíse Chates (2016) movimentou-se junto a um grupo de pesquisadores/as discentes, se propondo a pensar o processo de implantação da lei 11.645/2008 no próprio IFBA, destacando, sempre que possível, a relação entre ensino comum de sociologia e ensino de relações étnico-raciais. As pesquisadoras concretizaram uma ampliação das formas como o IFBA lida com a temática indígena em seu âmbito institucional, inicialmente numa etapa investigativa, realizando entrevistas com servidores e alunos/as para mapear o assunto, e em seguida construindo um curso de extensão específico destinado aos discentes, servidores/as e membros da comunidade externa do Instituto. A pesquisa reflete como a interface da tríade do ensino, pesquisa e extensão no IFBA traz um espectro de múltiplas formas de trabalhar com a temática indígena numa perspectiva que abrange, inclusive, a comunidade local onde o campus está inserido. Para a pesquisadora, essa conexão é essencial, inserindo a questão indígena 
nas escolas de modo a combater as opressões sistematizas e as lógicas estigmatizadoras lançadas sobre os povos indígenas.

É a partir dessa conexão que esse trabalho ganha corpo. Entendo a extensão como espaço que possibilita a construção efetiva de redes de diálogo entre povos indígenas e a comunidade escolar. Em reflexo a isso, no tópico seguinte trago as atividades de extensão nos Institutos Federais da Paraíba mapeando as ações voltadas à temática indígena, em especial, as atuações colaborativas junto aos povos indígenas paraibanos, envolvendo seus territórios e suas práticas ancestrais.

\title{
2 Extensão, cultura e temática indígena nos IFPB
}

\begin{abstract}
Entendida como prática acadêmica que interliga as atividades de Ensino e de Pesquisa com as demandas dos diversos segmentos da sociedade, o Instituto Federal da Paraíba consolida, através da Extensão, a formação de um profissional cidadão e se credencia junto à sociedade como um espaço privilegiado de produção e difusão do conhecimento na busca da superação das desigualdades sociais. ${ }^{1}$
\end{abstract}

A rede de extensão do IFPB é construída em interseção com as atividades de pesquisa e ensino, trazendo como diferencial um maior apelo para atividades vinculadas a comunidades locais. A partir da Política de Extensão do IFPB, as ações de fomento às atividades de extensão são construídas de forma abrangente, abraçando ações que "possibilitem uma participação crítica e dialógica de integração social e territorial, de aprofundamento da democracia, de combate à exclusão social, à fome e à miséria, de defesa do meio ambiente e da diversidade cultural e regional" (MEDEIROS, 2016, p. 30). Para viabilizar essas ações, a Pró-reitoria de Extensão e Cultura do IFPB possui um leque de atuação, indo desde a criação e manutenção de núcleos de extensão e cultura, até ao lançamento de editais voltados ao financiamento de ações específicas, como as que serão abordadas nesse trabalho.

Num olhar voltado às atividades de extensão universitária num contexto nacional, Laura Soares enfatiza a criação do Fórum de Pró-Reitores de Extensão das Instituições Públicas de Educação Superior Brasileiras (FORPROEX), no período da

\footnotetext{
1 Politica de Extensão e Cultura do IFPB. Disponível em: https://www.ifpb.edu.br/proexc/sobre/politicade-extensao.
} 
redemocratização de 1987, como fator essencial para a consolidação do caráter de promoção a iniciativas populares e democráticas de extensão universitária:

Dentro desses balizamentos, a produção do conhecimento, via extensão, se faria na troca de saberes sistematizados entre a universidade e a sociedade, tendo como consequência a democratização do conhecimento, a participação social efetiva na atuação da universidade e uma produção científica resultante do confronto com a realidade (SOARES, L., 2011, p. 570).

De forma geral, as ações de ensino e pesquisa são tomadas como imprescindíveis ao espaço universitário por serem indissociáveis dos processos de produção de conhecimento científico, no entanto, de acordo com Zimmermann e colaboradores (ZIMMERMANN et al, 2018), a extensão se consolida principalmente diante da construção de diálogos intra e extramuros universitários. Entende-se a extensão como atividade realizada no intuído de popularizar o conhecimento acadêmico e viabilizar a execução de ações em conjunto com as comunidades locais, especialmente as populações em contexto de vulnerabilidade social. A extensão desenvolvida no espaço universitário contribui para o aprofundamento das redes de atuação entre a instituição e a região na qual ela está inserida, construindo caminhos de mão dupla onde extensionistas e comunidade externa podem realizar uma troca de saberes, num rompimento entre as hierarquias de conhecimentos convencionais nas instituições acadêmicas.

É nessa ótica que esse trabalho se volta ao mapeamento das ações de extensão vinculadas à temática indígena no IFPB. Metodologicamente, realizei uma seleção das ações que se desenvolveram entre 2016 e 2019, buscando perceber se essas ações são realizadas com e sobre os povos indígenas. Levando em consideração a inserção do IF na Paraíba, pesquisei por palavras-chave voltadas à temática indígena e aos povos indígenas paraibanos $^{2}$ nos editais promovidos pela Pró-Reitoria de Extensão e Cultura (PROEX) ${ }^{3}$ de toda a rede do IFPB, sendo eles os de projetos de extensão (PROBEX Projeto, Cultura em Rede e Rede Rizoma), programas de extensão (PROBEX Programa e Programa de Integração Escola Comunidade - PIEC), edital de eventos (Programa Institucional de

\footnotetext{
${ }^{2}$ As palavras-chave utilizadas: "indígena", "índio", "território", "tradicional”, "etnia”, "étnico", "tabajara”, "potiguara", "baía da traição", "Rio Tinto", "Marcação" e "Conde".

3 Os referidos editais podem ser encontrados na aba EDITAIS, classificados por ano: https:// www.ifpb.edu.br/proexc/editais/extensao.
} 
Apoio a Eventos de Extensão e Cultura) e o edital de prestação de serviço (Programa Institucional de Apoio à Prestação de Serviço).

É importante salientar que o escopo dessa pesquisa se voltou apenas às submissões aprovados nos editais de extensão do IFPB, visto que apenas estes são públicos no site oficial da instituição, desse modo, não pretendo trazer constatações a respeito de projetos elaborados que não vieram a ser aprovados. Houve tentativa de contato, para levantamento de dados a respeito das referidas extensões, tanto com a PROEX da Reitoria Geral do IFPB quanto com o Departamento de Inovação, Pós-Graduação, Pesquisa, Extensão e Desafios Acadêmicos (DIPPED) do campus João Pessoa, mas não se obteve sucesso.

No que tange às ações de extensão promovidas pelo IFPB, faz-se necessário destacar a existência de um Núcleo de Extensão e Cultura voltado especificamente à temática indígena, com sede no campus Avançado de Cabedelo. O Núcleo de Resgate Cultural dos Ancestrais Paraibanos: Refazendo as trilhas indígenas do litoral norte (Lucena) ao Cariri paraibano (Serra Branca) foi formalizado no ano de 2016, sendo inserindo num contexto de fomento a ações sistemáticas de extensão pertencentes à REDE RIZOMA, junto aos demais núcleos do $\mathrm{IFPB}^{4}$. O núcleo propõe ações que "refaçam as trilhas das principais tribos indígenas que povoam a Paraíba, as quais deixaram um patrimônio cultural presente na forma de viver do povo paraibano" (SOUSA; MEDEIROS, 2016, p. 47), e mobiliza a importância dos povos indígenas na Paraíba, estruturando ações e promovendo reflexos em vários setores da extensão em campus variados do IFPB.

Em suas ações iniciais, em 2016, o núcleo mostra uma inserção que traz um enfoque nos povos indígenas como elementos formadores da cultura paraibana. A coordenadora do núcleo, Keitiane Silva, afirma que "não podemos resgatar a cultura de forma seletiva, é preciso resgatar as vozes e as histórias dos nossos ancestrais indígenas” (Assessoria de Comunicação do IFPB) ${ }^{5}$, e nesse sentido, o núcleo traz ações concretas

\footnotetext{
${ }^{4}$ Mais informações em: http://www.ifpb.edu.br/relacoes-internacionais/assuntos/nucleos-de-extensao/nu cleos-de-extensao-rede-rizoma.

5"Campus Avançado Cabedelo Centro promove resgate cultural de comunidades" - matéria publicada no site oficial do IFPB, em 2016. Disponível em: http://editor.ifpb.edu.br/campi/campi-em-implantacao/ noticias/2016/05/campus-avancado-cabedelo-centro-promove-resgate-cultural-de-comunidades.
} 
com os povos indígenas Potiguara e Tabajara da Paraíba em seus territórios e também na comunidade juremeira do Sítio Acais, na cidade de Alhandra no Cariri paraibano. As ações do núcleo devem ser problematizadas na medida em que são margeadas pela noção de "resgate cultural" ou mesmo de "tribos indígenas", corroborando, de certa forma, com o ideal de indígena atrelado ao passado romântico da identidade brasileira ou, nesse caso, paraibana. No entanto, várias ações foram viabilizadas e construídas no âmbito desse núcleo de extensão, e trazem colaborações significativas (várias delas analisadas nesse trabalho) em ação direta com os povos indígenas do estado, portanto, o núcleo pode ser considerado como avanço na implementação da Lei 11.645/2008.

\subsection{Extensão e povos indígenas: por dentro dos editais PROEX}

Além do referido núcleo de pesquisa, a análise de dados deste trabalho foi feita em quatro aspectos, abrangendo as interfaces de fomento às atividades de extensão promovidas pela PROEX para todos os campi do IFPB. No que tange aos projetos de extensão, analisamos os resultados referentes aos editais 'Programa Institucional de Bolsas de Extensão e Cultura: PROBEX PROJETO' (4 edições, uma por ano entre 2016 e 2019); 'Programa Institucional de Apoio ao Fortalecimento dos Núcleos de Extensão da “Rede Rizoma IFPB: Tecnologia em Extensão" PRORIZOMA' (apenas uma edição em 2017), e por fim, o edital 'Cultura em rede: fomento à articulação de grupos culturais e acadêmicos' (duas edições, em 2017 e 2018). ${ }^{6}$

No ano de 2016, 4 projetos se vinculavam à temática indígena, 2 dos 100 projetos aprovados no PROBEX Projeto e outros 2 referentes aos 22 aprovados no edital da Rede Rizoma. Já no ano de 2017, nenhum dos projetos financiados foi destacado, seja no PROBEX Projeto, que teve 141 bolsas disponibilizadas, ou no Cultura em Rede, com 16 bolsas. Em 2018, apenas 3 projetos entre os 168 disponíveis pelo edital PROBEX Projeto traziam à tona relações étnicas indígenas, mas não foi encontrado nenhum dentro dos 9 projetos aprovados no edital Cultura em Rede. 2019, ano com apenas um edital de

\footnotetext{
${ }^{6}$ Além desses editais, no ano de 2016, também tivemos acesso aos projetos realizados sem apoio financeiro no âmbito do Fluxo Continuo de Projetos de Extensão. Constam 58 projetos executados, sendo que nenhum relacionado à temática indígena.
} 
fomento a projetos, encontramos 178 vagas apenas no edital PROBEX Projeto, sendo 3 destas ocupadas por ações vinculados à temática indígena.

Proporcionalmente, de todos os projetos aprovados em cada edital, o Rede Rizoma se sai melhor em relação à inserção da temática indígena, sendo 2 de 22 projetos (9,09\% do total). Quanto às duas edições do edital Rede de Fomento, nenhum dos 25 projetos se vinculou às questões indígenas. Já nas 587 bolsas ofertadas pelas 4 edições do edital PROBEX Projeto, constatamos que apenas 9 (1,53\% do total) trouxeram à tona, direta ou indiretamente, a temática indígena. Somando-se todos os projetos aprovados, temos uma proporcionalidade de apenas $1,73 \%$ (11 de 634 projetos) do total de ações financiadas por meio dos editais para projetos de extensão e cultura da PROEX nos campi do IFPB. A seguir, evidencio esses 11 projetos, descrevendo, de forma breve, as propostas de atividades que constam em seus resumos.

Os projetos foram categorizados em dois sentidos. Primeiro trago à tona os 8 projetos realizados em colaboração direta com os povos indígenas do estado da Paraíba, com ações construídas nos territórios Tabajara e Potiguara ou com a participação dos indígenas dessas etnias. Em seguida, trago os outros 3 projetos que se voltam a práticas de ensino, mas não são realizadas de forma colaborativa ou mesmo têm como foco as comunidades indígenas, promovendo ações de ensino transversais pautando a temática indígena em segundo plano.

Entre a primeira categoria de projetos estão o Cartografia afetiva, cultural e ambiental da Barra de Mamanguape (PROBEX/2018 - Reitoria) e o Projeto barra VIVA: floresta atlântica e seus ecossistemas associados - manguezal e restinga nas vivências de educação ambiental para uma escola municipal de Rio Tinto, Paraíba (PROBEX/2018 - Reitoria). O primeiro deles se guia pela ação colaborativa entre o Núcleo de Resgate Cultural dos Ancestrais Indígenas e outros dois núcleos da Rede do IFPB, propondo a realização de momentos de sensibilização, elaboração de mapas afetivos e oficinas no contexto escolar. $\mathrm{O}$ segundo traz iniciativas que visam ampliar a educação ambiental, pautando a preservação dos ecossistemas por meio de oficinas “ecopedagógicas". Ambos os projetos se vinculam à sustentabilidade na Barra de Mamanguape, zona de sobreposição entre o território Potiguara e a Área de Proteção Ambiental (APA) do rio Mamanguape. 
O projeto Comunidade de mãos dadas com o ambiente, saúde e qualidade de vida! (PROBEX/2019 - Cabedelo) traz uma ação conjunta entre comunidades de pescadores/as de Cabedelo/PB e Baía da Traição/PB. A partir dele os/as estudantes do IFPB devem desenvolver propostas de atuação voltadas à melhoria em saúde e meio ambiente, tendo em vista as especificidades indígenas e ribeirinhas das duas cidades. $\mathrm{O}$ projeto prevê a concretização de um diálogo colaborativo diretamente nos territórios em questão, incluindo espaços de educação não-formal, numa tentativa de melhorar as relações humano-natureza.

O projeto MOVIBEM: a ciranda dos saberes com povos tradicionais (PROBEX/2018 - João Pessoa) tem suas atividades focadas na reforma de uma oca na aldeia Gramame, do povo Tabajara do Conde, alinhada à construção de uma horta comunitária no quilombo Mituaçu, promovendo a troca de saberes entre essas duas comunidades tradicionais e estudantes e servidores/as do IFPB. O projeto propõe um rompimento com o olhar unilateral dos saberes, promovendo diálogos entre conhecimentos tradicionais de permacultura e bioconstrução, descentralizando-se das ações estritamente acadêmicas. Assim como o projeto anterior, o Casa de farinha: um beneficiamento para a comunidade tabajara localizada no município de Conde, estado da Paraíba (PROBEX/2018 - João Pessoa) traz uma abordagem semelhante em colaboração com os povos Tabajara e o IFPB. Essa ação propõe uma assessoria voltada à elaboração de um anteprojeto de construção para casas de farinhas nas aldeias Vitória e Barra de Gramame.

Enquanto os resumos abordados até agora dizem respeito ao edital PROBEX Projeto, os dois seguintes são realizados por meio do edital de apoio à implantação de núcleos de extensão da "Rede Rizoma IFPB: Tecnologia em Extensão". O primeiro deles, Visibilidade do toré da aldeia Potiguara de Tramataia (REDE RIZOMA Projeto/2016 - Reitoria), parte de experiências anteriores do Núcleo de Resgate Cultural dos Ancestrais Paraibanos, neste caso se propondo a realizar apresentações, eventos e oficinas de mobilização cultural na apresentação do toré dentro e fora das aldeias. Por último, Salvaguarda, registros e cidadania nas aldeias indígenas de Tramataia e Três Rios (REDE RIZOMA Projeto/2016 - Reitoria) também se vincula à aldeia Tramataia, pautando a construção de uma biblioteca para a comunidade, trazendo a inclusão de 
materiais que promovam o fortalecimento dos direitos cidadãos das comunidades tradicionais.

Novamente no âmbito dos Projetos PROBEX, temos o projeto Direitos humanos e diversidade: formação de jovens na Escola Estadual Pedro Augusto Porto Caminha/Jaguaribe/JP (PROBEX/2019 - João Pessoa) ficando entre as duas categorias elencadas nesse trabalho. O projeto se volta ao fomento de uma educação pautada pelos direitos humanos numa escola próxima ao IFPB, em contexto não indígena, no qual, uma das interfaces para o desenvolvimento dessa ação é a visita direta a comunidades indígenas. Mesmo pressupondo a realização de encontros junto a indígenas no intuito de discutir sobre as especificidades dos direitos humanos, essa atividade não diz respeito apenas a esses povos ou é construída com base direta nos seus territórios. Enquanto isso, o Coletivo Hipátia: conhecimento e empoderamento feminino em ação (PROBEX/2019 - Reitoria) se propõe a construir redes de diálogos voltados à luta por igualdade de gênero na cidade de Cabedelo/PB. Esse projeto se volta à discussão de várias temáticas dentro do seu tema geral, entre elas estão citadas mulheres indígenas, assim como negras, como população em maior contexto de vulnerabilidade. Mesmo sendo voltados a uma temática mais abrangente, esse projeto e o projeto anterior trazem à tona ações educativas que pautam a questão indígena de forma transversal, guiadas pela a existência contemporânea desses povos, a exemplo dos direitos indígenas e dos reflexos da desigualdade de gênero sobre as mulheres indígenas.

Os projetos a seguir não pressupõem ações realizadas em colaboração direta com os povos indígenas na Paraíba, se limitam ao diálogo em segundo plano. É o caso de Importância das pinturas rupestres e outras evidências históricas encontradas na região do município de Algodão de Jandaíra-PB (PROBEX/2016 - Campina Grande) que traz um enfoque específico para as pinturas rupestres encontradas na cidade de Algodão de Jandaíra. O projeto enfatiza o caráter indígena na formação da população local, trazendo à tona a necessidade de preservação dos sítios onde encontram-se as pinturas rupestres. Outro exemplo é O cinema e as outras histórias nas escolas: cidadania e diversidade étnica na construção de uma história social do Brasil (PROBEX/2016 - Patos) que se constrói a partir de um panorama contextual histórico utilizando como interface o filme "Uma história de amor e fúria" (UMA HISTÓRIA, 
2013), narrativa marcada pela menção da resistência dos povos indígenas ao processo de colonização. Essas duas ações são realizadas num sentido que já foi discutido neste trabalho, vinculando o indígena ao passado ancestral do Brasil-Nação, sem trazer elementos que evoquem suas existências na atualidade.

Quanto aos programas de extensão, o único edital que consta entre os anos analisados é o PIEC (2016-2018), que se tornou PROBEX PROGRAMA em 2019. No ano de 2016 e de 2017, foram aprovados 22 projetos em cada um dos editais, sendo apenas 1 projeto por ano vinculado à temática indígena. No ano de 2018, aprovaram-se 19 projetos, sendo novamente penas 1 vinculado à questão. Já em 2019, foram 32 projetos aprovados, incluindo 2 que se vinculam à temática indígena. Na soma de todos os programas aprovados, apenas 5 projetos $(5,26 \%)$ dos 95 aprovados, vinculam-se à temática indígena, os quais foram abordados neste trabalho.

O primeiro dos programas, o Programa assessoria jurídica popular do IFPB (PIEC/2016 - Reitoria) é o único do ano de 2016, propondo a construção de uma rede de assistência jurídica gratuita para a população das cidades de Marcação, Rio Tinto, Lucena e Cabedelo, incluindo os povos Potiguara dessa região. O programa se oficializa na interface do Núcleo de Resgate dos Ancestrais Paraibanos, assim como dos cursos técnicos subsequentes em Pesca e em Serviços Jurídicos, presentes em Lucena/PB e Cabedelo/PB, respectivamente. $\mathrm{O}$ resumo indica a visita às comunidades abrangidas pelo programa viabilizando ações de mediação de conflitos, sejam eles coletivos ou individuais. Já o Ciclo de formação na APA da Barra do Mamanguape (PIEC/2017 Reitoria), assim como o anterior, também se concretiza a partir do Núcleo de Resgate dos Ancestrais Paraibanos, propondo a promoção de cursos voltados a atividades pesqueiras, preservação ambiental e manejo do território e do rio Mamanguape. O projeto prevê a realização de oficinas ministradas pelos/as estudantes dos cursos de Guia de Turismo, Pesca e Serviços Jurídicos, junto a colaboradores/as do Instituto Chico Mendes, destinados a moradores/as de APA do rio Mamanguape, que se sobrepõem à área de 9 aldeias do Território Potiguara e do Potiguara de Monte-mor.

O programa Ritmos, ritos e danças afro-indígenas (PIEC/2018 - João Pessoa) traz ações integrativas entre membros do Grupo Raízes (Situado na ladeira da Borborema, centro de João Pessoa) e estudantes do IFPB, executando oficinas artísticas dentro do 
campus. O projeto pressupõe também a capacitação para que os alunos produzam artesanatos com reciclagem e promoção de rodas de conversa sobre a ancestralidade negra e indígena. Apesar de mencionar a temática indígena, este programa não prevê a colaboração direta com as comunidades indígenas paraibanas.

\section{Em 2017, o Inventário cultural do município do Conde (PROBEX} PROGRAMA/2019 - Reitoria) emerge a partir da colaboração entre IFPB, por meio do Núcleo de Resgate dos Ancestrais Paraibano, com a Prefeitura Municipal do Conde visando à capacitação de condutores culturais e guias turísticos informais para a cidade. Pretendia construir inventários junto às comunidades quilombolas, pesqueiras e do povo Tabajara. Também do ano de 2019, o projeto Meliponicultura do IFPB Cabedelo (PROBEX Programa/2019 - Cabedelo), não vinculado diretamente às comunidades indígenas da Paraíba, pressupõe a captura de colônias de abelhas numa perspectiva menos prejudicial ao meio ambiente, dando enfoque principal ao uso das técnicas desenvolvidas pelos povos indígenas Kayapó. O projeto propõe um resgate do que esse povo "conhecia" e das técnicas das quais "faziam uso", equivocando-se ao trazer concepções que vinculam os indígenas Kayapós ao passado, como se suas técnicas precisassem ser resgatadas, quando, na verdade, esses povos existem e suas práticas de meliponicultura são praticadas veementemente em suas aldeias nos dias atuais (PEQUENO, 2004).

Quanto às iniciativas de fomento a Eventos promovidos pela PROEX, encontramos o Programa Institucional de Apoio a Eventos de Extensão e Cultura (PROEVEXC), com 74 eventos aprovados, sendo apenas 1 (1,35\% do total) deles vinculado aos povos indígenas. O Festival Estadual de Cultura e Memórias Indígenas (Eventos/2016 - Reitoria) é desenvolvido pelo Núcleo de Resgate dos Ancestrais Indígenas, sendo realizado nas cidades de Cabedelo/PB e Serra Branca/PB, e pretende promover feiras de artesanatos, apresentações com indígenas da aldeia Tramataia, assim como espaços de conversas, e um desfile cívico, no intuito de enfatizar o caráter indígena das terras paraibanas, seguindo os 'Caminhos dos Cariris', guiado pelas artes rupestres do município Serra Branca/PB.

Por fim, em relação às atividades de prestação de serviços, encontramos o Programa Institucional de Apoio à Prestação de Serviço, no qual apenas 2 projetos $(3,84 \%$ do total) se vinculam aos povos indígenas em meio aos 52 aprovados no período 2016 a 


\section{A Incubadora de artesanato indígena da aldeia de Tramataia - Marcação/PB}

(Prestação de Serviço/2016 - Reitoria) propõe uma capacitação junto a artesãs indígenas da aldeia Tramataia do povo Potiguara, visando à manutenção das atividades de formação e produção de artesanatos. Além disso, a incubadora prevê a capacitação para promoção nas mídias digitais, numa busca pelo fortalecimento da autonomia das mulheres indígenas. Por outro lado, o projeto Lajedo.com: potencializando o empreendedorismo, cultura e história no Lajedo do Marinho - Boqueirão-PB (Prestação de Serviços/2019 - Cajazeiras) propõe o desenvolvimento de um site a ser utilizado para atender a comunidade rural do distrito do Lajedo do Marinho, na cidade Boqueirão/PB. O serviço prestado pretende fomentar o potencial turístico da região, enfatizando o turismo etno-histórico por meio dos artefatos arqueológicos e do museu do Lajedo, assim como as atividades de turismo ambiental.

Dentre a seleção que realizei, algumas outras ações vinculam-se ao ensino de relações étnico-raciais, porém, os resumos indicam que os debates voltados especificamente aos povos indígenas e etnicidade são deixados de lado. A exemplo disso temos alguns projetos que mencionam as relações étnico-raciais abordando apenas, de uma forma mais geral, o ensino de diversidade e conscientização sobre direitos humanos. Alguns outros projetos até se voltam mais profundamente às questões raciais, vinculadas ao ensino do conceito de cultura e de identidade ou ao contexto de vulnerabilidade social, mas mantêm suas ações resumidas ao ensino de cultura e história afro-brasileira, ou ao alcance do movimento negro.

Em todas as ações vinculadas à extensão expostas neste trabalho, a participação dos povos indígenas, seja direta ou indiretamente, é crucial para boa efetivação dos projetos, de modo que não podem ser desconsideradas ao pensarmos o espectro das movimentações referente aos povos indígenas no eixo da extensão no IFPB. Percebemos que das 19 ações mapeadas, $13(68.42 \%$ do total) delas vinculam-se diretamente às comunidades indígenas Potiguara e/ou Tabajara em seus territórios, enquanto as 6 ações restantes trazem os povos indígenas em segundo plano. De modo geral, as atividades de extensão trazem o auxílio técnico a partir de áreas especializadas no âmbito dos cursos dentro do IFPB, como por exemplo, os auxílios na construção ou planejamento de habitações, móveis ou prédios de uso comunitário. Porém, não se restringe a essas 
atividades, fazendo também a promoção de atividades voltadas à mobilização cultural e cidadã dentro e fora das aldeias, assim como promovendo ações de ensino que acabam englobando os povos indígenas.

\section{Apontamentos finais}

Em entrevista realizada no dia 28 de agosto de 2019 com a coordenadora de extensão e cultura do IFPB, campus João Pessoa, percebemos que os editais de fomento têm sido cada vez mais o alvo de cortes de gastos e medidas de contenção de recursos dentro dos institutos federais, especialmente após o golpe promovido contra a presidenta Dilma Rousseff em 2016. Esse contexto se repete em relação ao Programa de Extensão do MEC, de abrangência nacional. No trabalho de Incrocci e Andrade (2018) visualizase a quebra de um longo período de crescimento das redes de fomento à extensão a nível nacional, com uma queda de 40 milhões de reais (mais da metade do total) entre os anos de 2015 e 2016, frente a um crescimento que se mantinha consolidado desde 2003.

A situação tem se agravado fortemente na rede de extensão interna do IFPB, ocasionando uma constante diminuição de recursos financeiros para execução das ações extensionistas, o que já culminou no cancelamento de editais específicos, situação que pude constatar na análise dos editais: nos anos de 2016, 2017 e 2018 tivemos pelo menos 2 editais para projetos de extensão por ano, enquanto mapeamos apenas 1 para todo o ano de 2019. Referente a essa diminuição, Roberta afirma:

Os projetos basicamente se mantêm em números, porém as propostas de editais vão diminuindo. Chegou-se há anos anteriores que eram 5 editais por ano. Esse ano [2019] por exemplo, a gente só lançou $3^{7}$, e mesmo assim todos os três estão com os auxílios contingenciados (informação verbal) ${ }^{8}$

De acordo com a entrevistada, o corte de gastos realizados em 2019 levou ao cancelamento de editais previstos para serem lançados pela PROEX da reitoria do IFPB, assim como os editais internos, promovidos pela Coordenação de Extensão, Cultura e Desafios Acadêmicos do próprio campus João Pessoa. Ela destaca ainda a existência de uma tendência a "andar para trás” no âmbito das atividades de extensão no IFPB:

\footnotetext{
${ }^{7}$ Referentes aos editais de Projetos, Programas e Prestação de Serviços.

${ }^{8}$ Fala de Roberta Paiva Cavalcante, coordenadora de Extensão, Cultura e Desafios Acadêmicos do IFPB/João Pessoa, obtida em entrevista realizada pelo autor em 28 de agosto de 2019.
} 
- Acredito que é uma tendência que a gente tá andando pra trás né. Porque a gente vinha com um fluxo de trabalhos, com uma produção, e de repente a gente tá tendo que voltar um pouco. Todos os extensionistas estão recuando e isso é muito negativo, porque você tá ali naquela evolução e de repente você tem que recuar. Eu entendo que esse recuo não se dá só nos projetos, ele se dá nos resultados dos projetos, então todos serão impactados.

— Você acha que isso pode se intensificar nos projetos vinculados as questões étnico-raciais?

- Sim. Porque esses projetos eles ajudavam a conscientização. A grande maioria dos projetos trabalhavam na forma de conscientização, de empoderamento, de respeito. Então a partir do momento que ocorre essa diminuição e esse recuo isso afeta também essa questão (informação verbal) ${ }^{9}$

Nas reflexões compartilhadas ao longo desse trabalho, especialmente diante da bibliografia analisada, é perceptível que a forma como as escolas lidam com a temática indígena ainda não ocorre de modo a sanar efetivamente o previsto na Lei 11.645/2008. Numa perspectiva geral, percebemos a prevalência do ideal do indígena estigmatizado (OLIVEIRA, 2016; BANIWA, 2006; SILVA, E., 2017) frente a alguns poucos esforços no âmbito do ensino, sem ações majoritárias intercaladas com a quebra do paradigma colonial, promotoras da valorização da diversidade étnica e da efetivação de uma práxis antirracista. Entretanto, mesmo em pequeno número podemos encontrar casos de aplicação efetiva da lei, como no avanço quantitativo ao trabalhar a temática indígena nos livros didáticos (SILVA, M., 2010; SOARES, V., 2020), na significativa implementação de disciplinas voltadas a discussões étnico-raciais nas universidades (SANTANA, 2017), e mesmo nas atividades pontuais realizadas por professores da educação básica (RUSSO; PALADINO, 2016) ou extensionistas nas instituições federais (CHATES, 2018).

De modo conclusivo, nesta pesquisa percebemos que não é suficiente a quantidade de ações de extensão vinculadas à temática indígena dentro do IFPB, e a situação se agrava ainda mais com a redução do financiamento aos editais específicos de extensão. A falta de financiamento a esse tipo de projeto incide diretamente sobre a execução de projetos voltados à temática indígena, no sentido em que estes projetos têm nos editais de extensão, um de seus principais expoentes de execução, como podemos perceber nas ações aqui destacadas. Tornam-se nítidos alguns bons resultados gerados a partir de iniciativas acerca da temática indígena, mas estas ainda não são suficientes. A necessidade de criação de redes de fomento dentro do IFPB e das demais instituições

\footnotetext{
${ }^{9}$ Idem.
} 
educacionais voltadas à viabilização de práticas que trabalhem com a temática indígena ainda é urgente.

A Pró-Reitoria de Extensão e Cultura, assim como os campi do IFPB de forma geral, ainda têm muito a caminhar até chegar a uma quantidade razoável e efetiva de trabalhos colaborativos junto/sobre os povos indígenas no âmbito da extensão. No entanto, entendemos que mesmo em pequena quantidade, os projetos indicam a movimentação de esforços positivos, ativando ações colaborativas junto a esses povos e promovendo ações sistematizadas e com um fluxo relativamente contínuo nos últimos quatro anos.

\section{Referências}

BANIWA, Gersem dos Santos L. O índio brasileiro: o que você precisa saber sobre os povos indígenas no Brasil de hoje / - Brasília: Ministério da Educação, Secretaria de Educação Continuada, Alfabetização e Diversidade; LACED/Museu Nacional, 2006.

BRASIL. Presidência da República. Lei n. 11.645/2008, de 10 de março de 2008. Altera a lei n. 9.394, de 20 de dezembro de 1996, modificada pela lei n. 10.639, de 9 de janeiro de 2003, que estabelece as diretrizes e bases da educação nacional, para incluir no currículo oficial da rede de ensino a obrigatoriedade da temática "História e Cultura AfroBrasileira e Indígena”. Diário Oficial da União, Brasília: Imprensa Nacional, 2008.

CHATES, Taise de Jesus. Ensino de sociologia e Lei 11.645/08: experiências de ensino, pesquisa e extensão no IFBA. Revista em Debate (UFSC), Florianópolis, n. 14, p. 122139, 2015. Disponível em: https://periodicos.ufsc.br/index.php/emdebate/article/view/ 1980-3532.2015n14p122/32248. Acesso em: 04/05/20.

FAISTING, André; AGUIAR, Márcio. Sociologia e antirracismo: a experiência do PIBID no desenvolvimento de práticas pedagógicas de combate ao racismo e valorização da diferença étnico-racial. Interfaces da Educação, Paranaíba, v.9, n. 25, p. 184-202, 2018. Disponível em: https://periodicosonline.uems.br/index.php/interfaces/article/view/2486 /2266. Acesso em: 04/05/20.

GRUPIONI, Luís Donisete Benzi. "Livros Didáticos e Fontes de Informações sobre Sociedades Indígenas no Brasil." In: SILVA, Aracy Lopes \& GRUPIONI, Luís Donisete Benzi. A Temática indígena na escola: novos subsídios para professores de $1^{\circ}$ e $2^{\circ}$ graus. Brasília: MEC/MARI/UNESCO, 1995.

INCROCCI, Lígia Maria de Mendonça Chaves; ANDRADE, Thales Haddad Novaes. O fortalecimento da extensão no campo científico: uma análise dos editais ProExt/ME. Revista Sociedade e Estado, Brasília, v. 33, n. 1, p. 187-212, 2018. Disponível em: 
https://www.scielo.br/scielo.php?script=sci_arttext\&pid=S0102-69922018000100187\& lng=pt\&nrm=iso\&tlng=pt. Acesso em: 05/05/20.

MEDEIROS, Vania Maria. A rede Rizoma como estratégia para cumprimento das políticas nacionais e institucionais de extensão. In: SOUSA, Beatriz Alves; MEDEIROS, Vania Maria (Orgs.). Rede rizoma: movimento de extensão no IFPB. João Pessoa: Editora do IFPB, 2016, p. 29-32.

OLIVEIRA, João P. de. O nascimento do Brasil e outros ensaios: "pacificação", regime tutelar e formação de alteridades. Rio de Janeiro: Contra Capa, 2016.

PEQUENO, Eliane da Silva Sousa. Trajetória de reinvindicação kayapó sobre a terra indigena Badjônkôre. Revista de Estudos e Pesquisas, Brasília, v.1, n. 2, p. 249-288, 2004. Disponível em: http://www.funai.gov.br/index.php/projeto-editorial/revista-deestudos-e-pesquisas. Acesso em: 05/05/20.

RUSSO, Kelly; PALADINO, Mariana. A lei n. 11.645 e a visão dos professores do Rio de Janeiro sobre a temática indígena na escola. Revista Brasileira de Educação, Rio de Janeiro, v. 21, n. 67, p. 897- 921, 2016. Disponível em: https://www.scielo.br/scielo.php? script=sci_arttext\&pid=S1413-24782016000400897. Acesso em: 05/05/20.

SANTANA, Paula. Práxis Antirracista, descolonização das mentes e a questão indígena em uma instituição federal de ensino superior do sertão pernambucano. Revista Anthropológicas, Recife, v. 28, n. 2, p. 112-140, 2017. Disponível em: https://periodicos. ufpe.br/revistas/revistaanthropologicas/article/view/236288. Acesso em: 05/05/20.

SILVA, Edson. Os Povos Indígenas e o Ensino: Reflexões e Questionamentos às Práticas Pedagógicas. Tópicos Educacionais, Recife, v. 23, n.2, p. 89-105, 2017.

SILVA, Maria da Penha da. A "presença” dos povos indígenas nos subsídios didáticos: leitura crítica sobre as abordagens das imagens e textos impressos. Minemosine Revista, v. 1, n. 2, 2010, p. 268-290. Disponível em: http://www.ufcg.edu.br/ historia/ mnemosinerevista/volume1/dossie_brasil-imperio/brasil-imperio-volume1-n2-juldez201 0.html. Acesso em: 04/05/20.

SOARES, Laura Tavares. CT\&I, desenvolvimento social e demandas locais: o papel daextensão universitária. Parcerias Estratégicas, v. 16, n. 32 (Parte 2), p. 555-574, 2011. Disponível em: http://seer.cgee.org.br/index.php/parcerias_estrategicas/issue/view/ 64/showToc. Acesso em: 05/05/20.

SOARES, Valclecia Bezerra. A construção do indígena nos materiais didáticos de sociologia: realizações e desafios. 2020. Trabalho de Conclusão de Curso (Curso de Licenciatura em Ciências Sociais) - Centro de Ciências Humanas, Letras e Artes, Universidade Federal da Paraíba, João Pessoa, 2020.

SOUSA, Beatriz Alves; MEDEIROS, Vania Maria (Orgs). Rede rizoma: movimento de extensão no IFPB. João Pessoa: Editora do IFPB, 2016. 
UMA HISTÓRIA de amor e fúria. Produção de Caio Gullane e Fabiano Gullane. São Paulo: Buriti Filmes, 2013. DVD (75 min), animação, son., color.

ZIMMERMANN, Marlene Harger; CRISOSTIMO, Ana Lucia; SILVEIRA, Rosemari Castilho Foggiatto. A extensão universitária intra/extramuros e a construção do conhecimento científico. In: CRISOSTIMO, Ana Lucia; SILVEIRA, Rosemari Castilho Foggiatto (Orgs). A extensão universitária e a produção do conhecimento: caminhos e intencionalidades. Guarapuava: Editora da UNICENTRO, 2017, p. 27-54. Disponível em: https://www3.unicentro.br/ppgen/wp-content/uploads/sites/28/2017/11/A-Extens\% C3\%A3o-Universitaria-e-a-Produ\%C3\%A7\%C3\%A3o-de-Conhecimento.pdf. Acesso em: 05/05/20.

Recebido em: 21/02/20.

Aceito em: 05/05/20. 